\section{Contaminating cancer genomes}

\section{By Chris Cain, Senior Writer}

Two European teams have pinpointed the DNA-protective enzyme 7,8-dihydro-8-oxoguanine triphosphatase as a chemically tractable target whose inhibition kills cancer cells by accelerating DNA damage. ${ }^{1,2}$ Both groups have identified collections of small molecule inhibitors of the enzyme-one of which is an isomer of cancer drug Xalkori crizotiniband both are looking to partner with industry.

The compounds could be useful to treat a range of tumor types, including $K$-Ras (KRAS)-mutant cancers.

The normal role of 7,8-dihydro-8-oxoguanine triphosphatase (NUDT1; MTH1) is to prevent DNA damage by cleaving oxidized dATP or dGTP, which can accumulate and inappropriately incorporate into the genome if left unchecked.

Recent studies have shown that MTH1 is overexpressed in Rasdependent cancers and can suppress oxidative damage. That finding suggested that inhibiting the target could be lethal to tumor cells. ${ }^{3}$

Thomas Helleday, a professor at the Karolinska Institute, became interested in MTH1 in cancer based in part on these earlier publications and his team's long-standing work on DNA-repair pathways.

"We wanted to find a DNA-repair target that could be more generally applicable to cancer by looking at phenotype instead of genotype and building on our knowledge that cancers have a higher load of DNA damage than normal cells," he told SciBX.

His team therefore started searching for candidate DNA-repair proteins that were not generally essential for cell growth but could be particularly important for cancer cell survival. MTH1 fit the bill.

In cancer cell lines, shRNA against MTH1 inhibited cell growth and decreased the incorporation of oxidized nucleotides compared with control shRNA. Expressing an shRNA-resistant, wild-type copy of $M T H 1$ restored cell growth, whereas expressing a catalytically dead mutant did not.

The researchers then synthesized small molecule inhibitors of the target, which Helleday's lab had previously helped crystallize in the course of studying DNA-repair pathways in normal cells. ${ }^{4}$

In vitro, the best compounds inhibited MTH1 with low nanomolar potency, and crystal structures identified their binding site on the protein. In a series of cancer cell lines and in xenograft mice with breast cancer, colon cancer or drug-resistant melanoma cells, one of the best compounds decreased growth compared with vehicle.

To confirm that the effect of the compounds was due to their engagement with MTH1 and not an off-target effect, Helleday's group expressed the bacterial homolog of MTH1, mutT, which is not inhibited by the compounds, in cancer cells. This reversed the cytotoxic effect of the compounds.

"This is the ultimate proof of an on-target effect," Helleday told SciBX.

Results were published in Nature.

\section{Same target, different routes}

A team led by Giulio Superti-Furga did not set out to interrogate MTH1 at all and came upon it while attempting to determine the target of a 15-year-old compound that had been synthesized by Schering-Plough Corp., SCH51344.

Schering-Plough was acquired by Merck \& Co. Inc. in 2009, and SCH51344 never entered clinical development for undisclosed reasons.

"For many years we had been building up the capability to identify targets from phenotypic screens using an unbiased chemical proteomic approach," said Superti-Furga, who is CEO and scientific director of the Research Center for Molecular Medicine of the Austrian Academy of Sciences (CeMM). "We searched the literature for interesting hits and found this compound, which was particularly active against Rastransformed cells and which had an unknown mechanism of action that was not thought to be through MAP kinase signaling."

His team synthesized a modified version of SCH51344 that could be affinity purified and then used mass spectrometry of cell lysates to fish out its targets. The top hits turned out to be MTH1 and adenosine kinase.

Inhibiting adenosine kinase had no effect on SCH51344-sensitive cells, suggesting that the compound was most likely killing cells by inhibiting MTH1. Indeed, the team confirmed that knockdown of MTH1 killed Ras-transformed cancer cells.

Superti-Furga then reached out to Helleday's group to ask for the protocols and reagents for the in vitro assays that would be needed to confirm SCH51344 as an inhibitor of MTH1 catalytic activity, unaware that Helleday's team also was pursuing the target.

Helleday told SciBX, "Giulio told us the story of how his team fished out the target with proteomics, so we sent our biochemist to his lab with the assays, and it turned out to be MTH1. It was a nice independent validation of the target."

\section{Xalkori surprise}

The CeMM lab began screening for inhibitors of MTH1 in collaboration with Stefan Knapp, a professor of structural biology at the University of Oxford and principal investigator of epigenetics and chemical biology at the Structural Genomics Consortium. The hypothesis was that existing kinase inhibitors, which often mimic ATP and thus are structurally related to MTH1's nucleotide substrates, might also act on the target.

The top hit from the screen was Pfizer Inc.'s Xalkori, an inhibitor of anaplastic lymphoma kinase (ALK) and c-Met receptor tyrosine kinase that is marketed to treat ALK-fusion-positive non-small cell lung cancer (NSCLC).

Although the compound exhibited reproducible activity within batches ordered from chemical suppliers, it had widely variable activity from batch to batch. 
After exhaustive testing, the team found that the $(S)$ enantiomer of crizotinib inhibited MTH1 with low nanomolar potency. The $(R)$ enantiomer-which is what Pfizer markets as Xalkori-did not inhibit MTH1.

"This is where serendipity stepped in again," said Superti-Furga. "If we hadn't received an optically impure crizotinib batch from one vendor and instead used only clinical-grade crizotinib given to patients, we would not have seen this result."

In collaboration with Knapp, the team solved the structures of the $(R)$ and $(S)$ forms of the compound bound to MTH1. The structures showed that the $(R)$ form adopts an unfavorable entropic interaction with the protein that precludes activity.

A proteomic approach then showed that although $(S)$-crizotinib potently targets MTH1 in KRAS-mutant colon carcinoma cells, it did not exhibit any significant affinity toward ALK, c-Met or any other kinase target of $(R)$-crizotinib.

"I've been doing these kinds of assays for 15 years, and the result was incredibly dramatic," said Superti-Furga. "Usually with kinase inhibitors you get a gradient of hits, some kinases bind a compound better than others, and then there is a tail. What was remarkable with $(S)$-crizotinib was that it is not binding to kinases at all, and in vitro studies confirmed this."

Superti-Furga was cofounder, scientific director and SVP of biology at proteomics company Cellzome AG before joining CeMM in 2004. GlaxoSmithKline plc acquired Cellzome in 2012.

In xenograft mice with KRAS-mutant tumors, $(S)$-crizotinib decreased tumor growth compared with $(R)$-crizotinib or vehicle.

Results were published in Nature alongside Helleday's work.

\section{Clinical moves}

Both teams are continuing to synthesize and optimize MTH1 inhibitors and are seeking development partners.

Helleday's compounds are covered by composition-of-matter patent applications, which are held by a foundation in his name. He hopes to partner or license the compounds to fund work in his lab.

"The people who work with me, half have come from industry; it is quite different from other labs. We have six teams: a basic science team, a medicinal chemistry team, a biochemistry team, in vivo pharmacology, biology and in vitro pharmacology. I want to make sure the funds flow back to the people who did the work," he said.

He continued, "We are good at derisking a target, and we can make great small molecules, but our competence is not in regulatory affairs or in GMP production or GLP toxicology. We have almost 100 people involved in this project, but we don't want to go into areas where we do not have the appropriate expertise."

Both Superti-Furga and Helleday said that Mth1-mutant mice are healthy, which is a promising sign from a safety standpoint. They acknowledged that additional safety work will need to flesh out side effects that could arise from chronic disruption of a DNA-repair pathway.

Superti-Furga said that his lab is looking to either partner with a pharmaceutical company or start a company with venture backing. His team has filed a patent application covering the use of $(S)$-crizotinib to treat cancer susceptible to MTH1 inhibition.

He told SciBX that he has synthesized additional compounds covered by composition-of-matter patents.

Superti-Furga said that he contacted Pfizer to discuss the findings prior to publication, but a confidential disclosure agreement was never entered into and no detailed discussions took place. He has not spoken to Pfizer since the publication of the papers.

Pfizer declined requests for comment.

Cain, C. SciBX 7(15); doi:10.1038/scibx.2014.418

Published online April 17, 2014

\section{REFERENCES}

1. Gad, H. et al. Nature; published online April 2, 2014; doi:10.1038/nature13181

Contact: Thomas Helleday, Karolinska Institute, Stockholm, Sweden e-mail: thomas.helleday@scilifelab.se

2. Huber, K.V.M. et al. Nature; published online April 2, 2014; doi:10.1038/nature13194

Contact: Giulio Superti-Furga, Research Center for Molecular Medicine of the Austrian Academy of Sciences, Vienna, Austria e-mail: gsuperti@cemm.oeaw.ac.at

3. Rai, P. et al. Oncogene 30,1489-1496 (2011)

4. Svensson, L.M. et al. FEBS Lett. 585, 2617-2621 (2011)

COMPANIES AND INSTITUTIONS MENTIONED

GlaxoSmithKline plc (LSE:GSK; NYSE:GSK), London, U.K.

Karolinska Institute, Stockholm, Sweden

Merck \& Co. Inc. (NYSE:MRK), Whitehouse Station, N.J.

Pfizer Inc. (NYSE:PFE), New York, N.Y.

Research Center for Molecular Medicine of the Austrian

Academy of Sciences, Vienna, Austria

Structural Genomics Consortium, Oxford, U.K.

University of Oxford, Oxford, U.K. 